\title{
Coulisses
}

Revue de théâtre

3 | Hiver 1991

Théâtre et université

\section{Théâtre et poésie}

\section{Geneviève Clancy}

\section{(2) OpenEdition}

Journals

Édition électronique

URL : http://journals.openedition.org/coulisses/1633

DOI : $10.4000 /$ coulisses. 1633

ISSN : 2546-9460

\section{Éditeur}

Presses universitaires de Franche-Comté

\section{Édition imprimée}

Date de publication : 1 février 1991

Pagination : 22

ISSN : 1150-594X

\section{Référence électronique}

Geneviève Clancy, «Théâtre et poésie », Coulisses [En ligne], 3 | Hiver 1991, mis en ligne le 04 juillet

2017, consulté le 22 octobre 2019. URL : http://journals.openedition.org/coulisses/1633 ; DOI :

10.4000/coulisses. 1633

Ce document a été généré automatiquement le 22 octobre 2019

Coulisses 


\section{Théâtre et poésie}

\section{Geneviève Clancy}


1 Ce monde que la poésie libère, les plans informulés auxquels elle façonne des profils d'urgence, l'attente d'inespérés qui soudain font silhouettes, le nommé de cette quête originaire de l'absolu et qui charge le poème d'un étrange reconnu.

2 Cette pensée intégrale de l'homme s'adressant à l'homme, a sa place à part entière dans l'Université quand elle a vocation de l'établir comme génératrice de devenir. Mais comment une présence poétique peut-elle voir le jour tant comme mémoire plurielle d'une humanité ancestraie que comme dimension opérant sur le réel dans son énonciation créatrice?

3 L'atelier de Besançon avait un peu pour tâche de dessiner les contours de la question. Il ne faut pas se cacher la réalité, la mise à l'écart de la poésie comme pensée du monde et comme agir est aussi à charge du processus universitaire qui la tient trop souvent comme fait de langage et territoire de la littérature.

Elle tient peu compte de sa part fondatrice et de sa puissance à réaliser en l'homme ce par quoi il se dépasse en s'exigeant sous les traits qui lui proposent de lui, l'image poétique, quand cette image l'arrache à l'enfermement des modèles pour lui proposer d'entreprendre ce qui le fonde.

5 La poésie a seule le pouvoir de sa langue, alors il faut accepter de quitter le terrain des langues qui s'exercent sur ou à propos d'elle. C'était l'enjeu de l'atelier. Non point d'écrire ou analyser comment un atelier de création poétique se tient à l'université mais le faire sentir au travers de ses réalisations. Nous nous sommes appuyés sur les cahiers de poétique constitués par Paris I et Paris VII. Chacun exposant son travail sur un an. La rencontre avec les poètes et leurs textes, la découverte du mot comme matière, l'approche des fragments les plus quotidiens, dans ce que la rigueur poétique dévoile d'eux : le ce qui est dans la forme où il est. Un objet, un fait divers approché avec tout ce que le poétique met en jeu de recherche, de découvertes, de mystères.

Encore une fois, tout cela ne pouvait être transmis qu'au coeur de ce qui l'avait généré. Le cahier trace, les chemins des poèmes qui le constituaient furent l'unique base de la communication.

\section{AUTEUR}

\section{GENEVIÈVE CLANCY}

Paris II 